\title{
Corrigendum
}

\section{Cost-Effective Analysis of Malaysian Neonatal Intensive Care Units}

Irene Guat Sim Cheah

Anna Padma Soosai

Swee Lan Wong

Teck Onn Lim

Journal of Perinatology (2005) 25, 295. doi:10.1038/sj.jp.7211254

Correction to: Journal of Perinatology (2005) 25, 47-53,

doi:10.1038/jp.7211196
Following publication of the above paper, the author has identified an error in the last sentence of the Results section of the abstract. The sentence should read: "The average cost-effectiveness ratio (CER) of neonatal intensive care for the study group infants was US\$3979 per survivor at 1 year of age (95\% confidence interval US\$3411, 5160).” 